\title{
Nodemcu Based Prototype Tool for Noise Detection
}

\author{
Florentinus Nino* \\ STMIK Widya Cipta Dharma, \\ Samarinda, 75123, Indonesia \\ ninos equipment@gmail.com \\ * Corresponding author
}

\author{
Azahari id \\ STMIK Widya Cipta Dharma, \\ Samarinda, 75123, \\ azahari@wicida.ac.id
}

\author{
Awang Harsa Kridalaksana id \\ Universitas Mulawarman \\ awangkid@gmail.com
}

Received: 2021-03-03; Revised: 2021-04-07; Accepted: 2021-04-26; Published: 2021-06-01

\begin{abstract}
Application of Prototype A tool for detecting noise based on NodeMCU is a prototype that can be used to detect sound noise and provide a warning if the sound exceeds the reasonable threshold that humans hear. The function of this system is to detect sound noise using the Analog Sound sensor V2. Then the data from the Analog Sound sensor V2 will be displayed in the form of a Led and if it has passed the threshold that humans hear, it will trigger turning on the buzzer as a warning and send automatically the decibel value, status and also if we want to check how much noise there is, we can type / telegram the sensor. Based on the data analysis carried out, Basically programming for building Prototype Tool for detecting noise based on NodeMCU using the $\mathrm{C}$ programming language with the help of Arduino IDE software and monitoring it using LED and Telegram. This research was made in order to facilitate controlling the noise in the environment.
\end{abstract}

Keywords- Prototype Tool, Detect noise, NodeMCU

\section{INTRODUCTION}

Sound is something that is very important in life, because it is with voice that a person can communicate with other people. With voice can also express life, with voice can convey the meaning and purpose of communicating. But on the one hand the sound can be something very bad for the balance of life on earth, namely we call it noise pollution. Like speaking out loud is an annoying habit in an office environment. Having a hard coworker can distract us from our work and hurt our productivity. Humans have the ability to listen to sound frequencies ranging from 20 hertz to 20,000 hertz. If the sound is below that limit (infrasonic), or above it (ultrasonic), it will not be heard by humans. Meanwhile, humans can also hear sounds on a decibel scale (noise level) from 0 (very low), to 140 decibels (high and painful sounds). If the sound heard is more than 140 decibels, there can be damage to the eardrum and the organs in the eardrum. (Yoga Persada, Achmad Rizal, Muhammad Ramdhani 2012). The maximum safe threshold for humans is 80 decibels. However, human hearing can tolerate more than 80 decibels, provided the exposure time is considered. Ideally, for eight hours a person works at 70 decibels.
Decibels, it takes about four hours. Noise level 95 decibels, two hours long working. And the noise level is 100 decibels, long working one hour. If a person works beyond the tolerable threshold, then in the long term they will experience hearing loss.

\section{LITERATURE REVIEW}

\section{A. NodeMCU}

According to the official website nodemcu.com (2014) "An open-source firmware and development kit that helps we to Prototype youth IOT product within a few luat script lines" (an open source firmware and development set that helps we to Prototype IOT product. in a few lines of the Loa script). NodeMCU consists of hardware in the form of System On Chip ESP8266 from ESP8266 made by Expressive System, as well as firmware used, which uses the Loa scripting irmwarean language. The term NodeMCU by default actually refers to the firmware used instead of the development kit hardware. NodeMCU is analogous to the ESP8266 ardiuno board. NodeMCU has packaged the ESP8266 into a compact board with various features like a microcontroller plus capabilities for Wi-Fi as well as a USB to Serial communication chip.

\section{B. Sound Sensor}

According to Angga Wahyu Pradana Siregar (2018), the Analog Sound Sensor V2 is a simple module that functions as a sound detector for the Arduino project. The V2 sound sensor can be added to the Arduino project, it can activate the actuator with certain sounds, whether it's the sound of the engine - the factory engine is running, whistling, knocking on the door, and so on. This module can be used with the Audio Analyzer to receive input in the form of sound from outside (Syahwil, 2013; Dinata, 2018). The specifications of the analog sound sensor V2 are as follows:

1. Power supply: 3.3 - 5VDC

2. Using the electret microphone sensor.

3. It has a data output in the form of an analog voltage, so it can be easily connected to an ADC or microcontroller that has an internal ADC.

4. Suitable for detecting door sounds, engine sounds, or noise sensors. 


\section{B. Breadboard}

According to Saf tari (2015), a breadboard is a kind of PCB board, but does not require soldering. Breadboards are widely used for assembling components, because by using a breadboard, prototyping does not require a soldering process. Due to its solder less nature, it does not require solder so that it can be reused and thus it is very suitable for use at this stage of the Prototype manufacturing process and helps in the design of electronic circuits.

\section{A. LED (Light Emitting Diode)}

According to Syam (2013), Light Emitting Diode (light-emitting diode), which is better known by its short form, LED, produces light when current flows through it. Initially, LEDs were only made in red, but now orange, yellow, green, blue and white are also available in the market. There are also infrared LEDs, which produce infrared light instead of visible light. A typical LED has a dome-shaped packaging made of plastic, with a protruding edge (rim) at the bottom of the dome, there are two domed terminal legs at the bottom of the dome. Usually, although this is not always the case, the cathode pins are shorter than the anode pins. The rim is made flat on the side adjacent to the cathode leg.

\section{B. Buzzer}

According to Yurindra (2017), Buzzer is an electronic device that emits monotone sound. This sound is generated by mechanical vibrations caused by an electric current. The received electric current is used for the oscillation process which results in vibrations between the two fields. These vibrations cause sound to be emitted through the resonant tube so that a tone is heard. Because of the monotone sound, there is only one 'beep' sound emitted by the buzzer. Buzzers are widely used for example in alarm clocks, distance markers when the car is parked, there are also refrigerators that sound when the temperature changes because we open the door too long.

\section{Waterfall}

According to Yurindra (2017), the characteristic of the Waterfall concept is a document-driven approach. Waterfall is a model that builds software based on the Software Life Cycle (SDLC), which is a model that has a structure starting from planning, analysis, design and implementation, so that the Waterfall development stage has a development model structure called linear and sequential. (Habibullah, 2012; Kadir, 2013). The waterfall model can be seen in Picture 1.

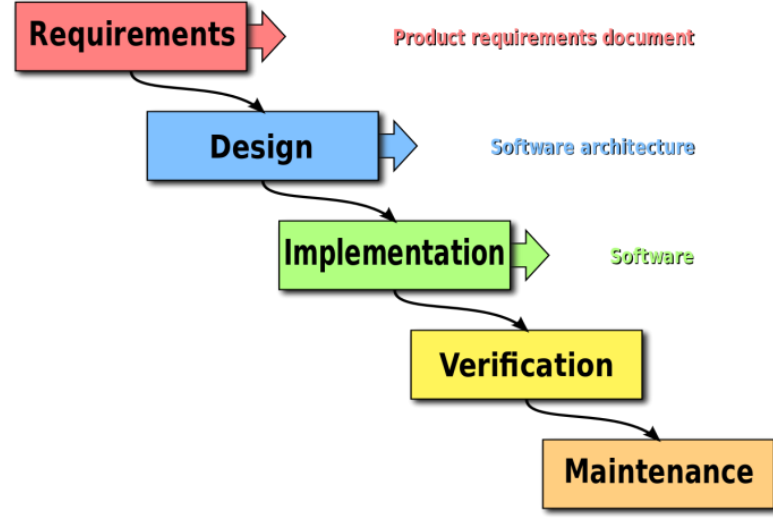

Picture 1. Waterfall Model (Waterfall)

In Waterfall, there are processes that can run simultaneously at a certain time which is often referred to as parallelism. The parallelism in the waterfall can be seen in Picture 2.

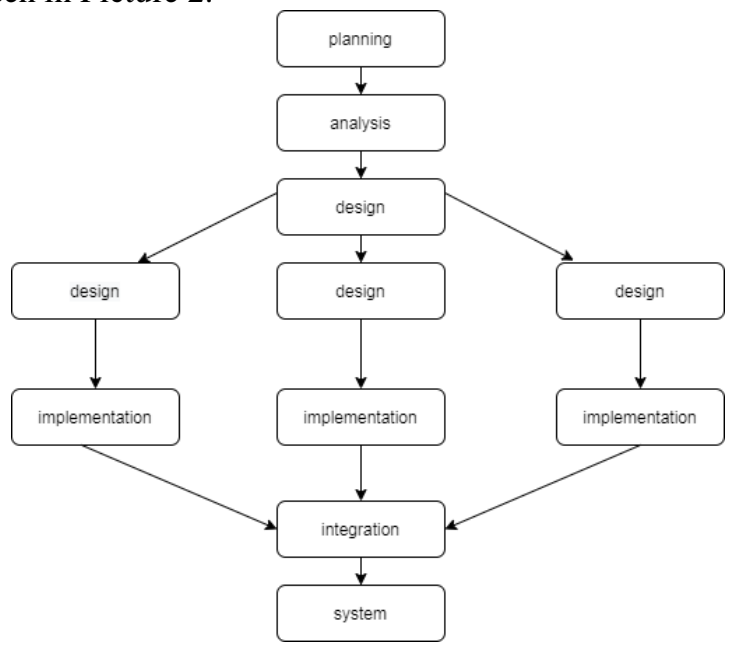

Picture 2. Parallelism in Waterfall

The stages of the Waterfall method are as follows:

1. Requirements Analysis

All software requirements must be met in this phase, including the expected software uses and software limitations. This information can usually be obtained through interviews, surveys or discussions. This information is analyzed to obtain documentation of user requirements for use at a later stage.

2. System Design

This stage aims to provide an overview of what should be done and how the results will look. This stage helps in specifying hardware and system requirements and defining the overall system architecture (Yudhanto, 2018).

3. Implementation

In this stage, programming is carried out. The software development is broken down into small modules which will be combined in a later stage. In addition, at this stage, an examination of the module being made is also carried out, whether it 
has fulfilled the desired function or not (Mulyana, 2012)

4. Integration and Testing

At this stage, the modules that have been made are merged and this test is carried out to find out whether the software made is in accordance with the design and there are still errors or not. (Pioto, 2014).

5. Operation and Maintenance

This stage is the end of the Waterfall model. The finished software is run and maintenance is done. This maintenance includes fixing errors that were not found in the previous step. Improved implementation of the system unit and increased system services as new requirements. help someone improve their performance in decision makers. A manager in a company can solve semi-structured problems, so managers and computers must work together as a problem-solving team in solving problems that are in a semi-structured area (Pratiwi, 2016).

When modeling in DSS development, the following steps are taken:

\section{Feasibility Study (Intelligence)}

In this step, goals are determined and procedure searches are carried out, data collection, problem identification, problem ownership identification, problem classification, and finally a problem statement is formed.

2. Design (Design)

At this stage, the model to be used and the criteria will be formulated. After that, look for an alternative model that can solve these problems. The next step is to predict the possible outcomes. Then determine the model variables.

3. Election (Choice)

After the design stage various alternative models and their variables were determined. At this stage, the model selection will be carried out, including the solution to the model. Furthermore, a sensitivity analysis was carried out, namely by replacing several variables.

4. Create a DSS

After determining the model, the following implements it in the DSS application.

Judging from the level of technology, DSS is divided into 3, namely:

1) Specific Decision Support System (DSS). Aims to help solve a problem with certain characteristics.

2) Decision Support System (SPK) Generators. A special software used to build and develop DSS. The SPK generator will make it easier for designers to build specific SPKs.

3) Decision Support System Equipment (DSS). In the form of software and hardware that is used or supports the construction of specific DSS or SPK generators.
Based on the level of support, the DSS is divided into 6, namely:

1) Retrieve Information Elements. This is the lowest support that a DSS can provide, namely in the form of selective access to information.

2) Analyze Entire File. In this stage, managers are given access to view and analyze a complete file.

3) Prepare Reports from Multiple Files. This kind of support tends to be needed since managers deal with many activities with one particular moment.

4) Estimate Decision Consequences. In this stage, it is possible for managers to see the impact of every possible decision.

5) Propose Decision. Support at this stage is a bit more advanced. An alternative decision can be presented before the manager for consideration.

6) Make Decision. This is the kind of support one would expect from a DSS. This stage provides a decision that is just waiting for the legitimacy of the manager to run.

\section{Alpha Testing}

Suhartono (2016) Alpha testing is one of the most commonly used software testing strategies in software development, it is specifically used by product development organizations with the aim that the system being developed avoids defects or failure of use. Alpha testing takes place on the developer's site by an internal team, prior to release to external customers. So that later when customers use this system they are not disappointed because of defect problems or application failures (Hardyanto, 2017; Persada, et al. 2014).

1. This test takes place on the developer's site. The developer observes the use of the application by the user, then the user records the findings that occur from application defects.

2. Alpha testing is the testing of an application at development and focuses on completion. Minor design changes can still be made as a result of alpha testing.

3. Alpha testing is usually carried out by a group that is independent of the design team, the development team but is still within the scope of the company, for example In-house software testing engineers, or software engineers.

Alpha testing is the final testing before the software is launched for the general user. This test has two phases:

1) In the first stage of alpha testing, the software is tested by the developer in the developer's internal environment. They use a software debugger, or hardware-assisted debugger. The goal is to catch bugs quickly.

2) In the second phase of alpha testing, the software is left to the software staff, for additional testing in an environment similar to the intended use. This is to simulate the actual test atmosphere or environment so that when the system is installed, there is no real 
system failure or defect. The software development cycle diagram in Picture 3.

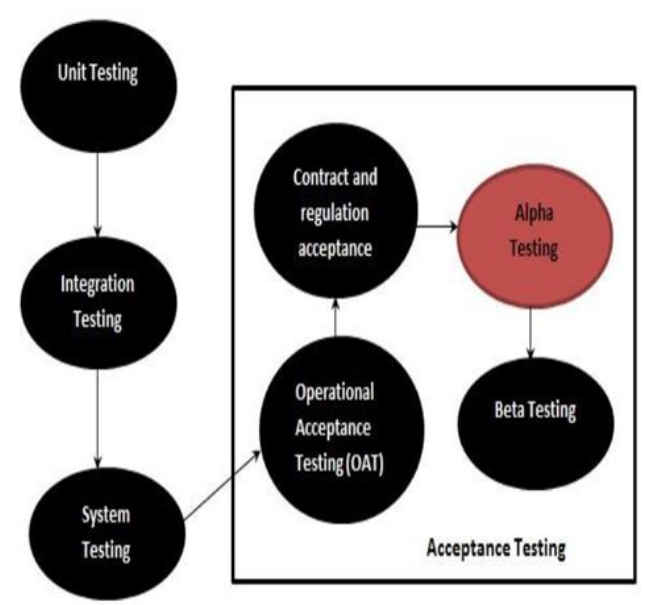

Picture 3. Software development cycle diagram.

\section{E. Black Box}

According to Pressman (2012), black-box testing is also called behavior testing, which focuses on the functional requirements of the software. That is, black box testing techniques allow one to derive a set of input conditions that will fully carry out all functional requirements for a program. Black-box testing is not an alternative to the white-box method. Rather, this method is a complementary approach to finding a class difference of white-box method errors. Black-box testing aims to find errors in the following categories:

1 . Wrong or incorrect function.

2. Interface error

3. Errors in data structures or database access external

4. Behavior or performance errors

5. Initialization and termination errors.

\section{RESEARCH METHODS}

Designing and building Prototypes by making temporary designs that focus on the appearance of the tool (for example by creating input and output formats) in accordance with the needs of the tools that have been defined previously (Kalengkongan, et al. 2018).

\section{A. Block Diagram}

The block diagram on the tool for detecting this noise will be illustrated in the following picture 4 .

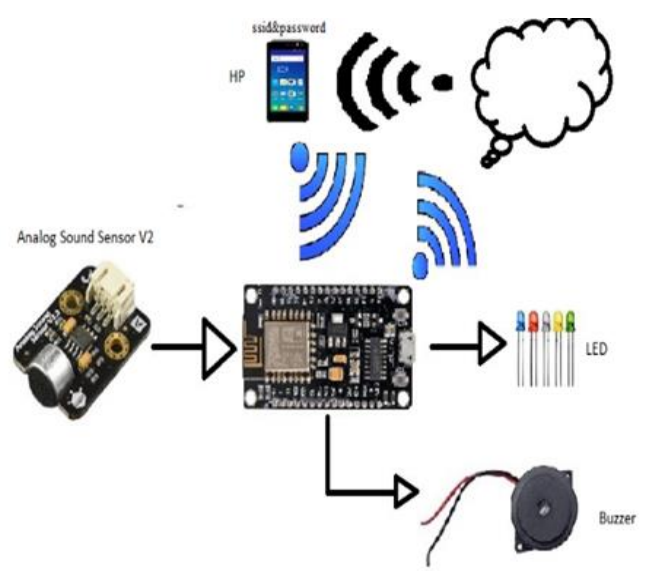

Picture 4. Block diagram

1. NodeMCU 1.0 is used as a microcontroller and as a center for processing incoming and outgoing data simultaneously and functions to fulfill the internet network needed to connect Telegram (Ellison, 2018).

2. Analog sound sensor v2 functions to capture sound voltage which will later be converted into electrical voltage.

3. Buzzer serves to provide sound alerts, when the sound threshold has exceeded the threshold.

4. LED lights serve as indicators, when the lights are still within safe limits, alert and dangerous.

\section{B. Schematic tool for detecting noise}

The schematic of a tool for detecting noise in the image is explained from the port and pin functions used in NodeMCU (Malau, et al. 2017). The schematic of the tool for detecting noise can be seen in Picture 5.

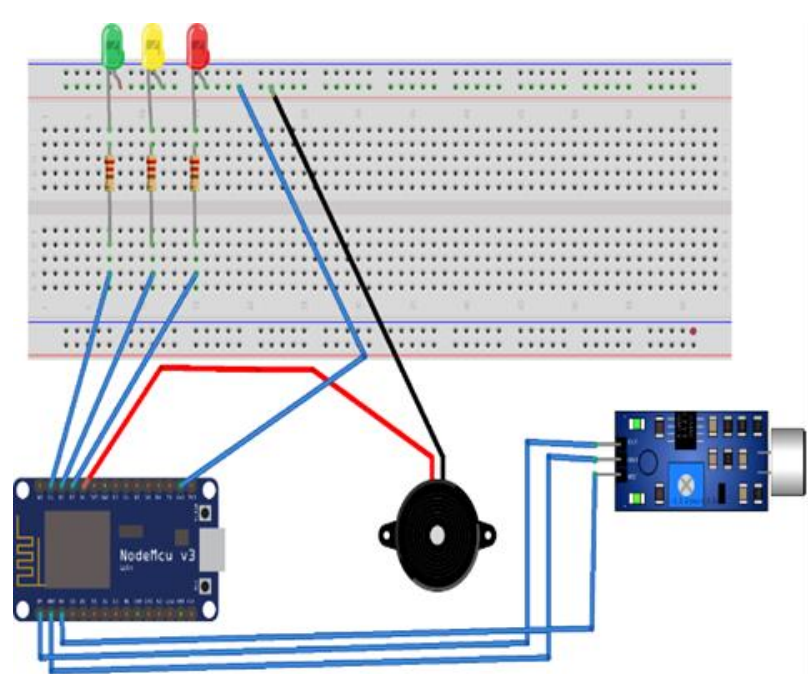

Picture 5. Schematic of tools for detecting noise

In the picture 5, the Analog Sound Sensor V2 is connected to NodeMCU where the pin out on the analog sound sensor is analog V2 to pin A0 At NodeMCU, the GND pin is analog sound sensor V2 to GND pin in NodeMCU, the VCC pin is analog sound sensor analog V2 to pin $5 \mathrm{~V}$ or UV pin In NodeMCU, GND Pin In NodeMCU, parallel breadboard is made to turn on the 
D4 pin of the buzzer, the lamp is on pin D1, pin D2, pin D3, pin D4.

\section{System Flowchart}

The system flowchart design in Picture 6 describes the entire flow in the main system of this tool (Yatini, 2010). In this noise detector, the first process that is executed is as follows. The system flowchart in Picture 5 describes the entire flow in the main system of this tool.

1. Start

2. Initials sensor, light and buzzer

3. Read sound sensor

4. Read the formula to find the $\mathrm{db}$. value

5. If sensor $1<=70$ then led pin D1 lights up

6. If sensor $1>70$ and $<=80$ then the led pins D1, D2 light up

7. If sensor1> 80 then the led and buzzer pins D1, D2, D3 light up

8. Furthermore, there is a condition when checking on the telegram. When typing / sensor, it prints $\mathrm{db}$. and if the $\mathrm{db}$. is already at $>=69-<=100$ the sensor will automatically send the status and $\mathrm{db}$. numbers. The system flowchart can be seen in Picture 6.

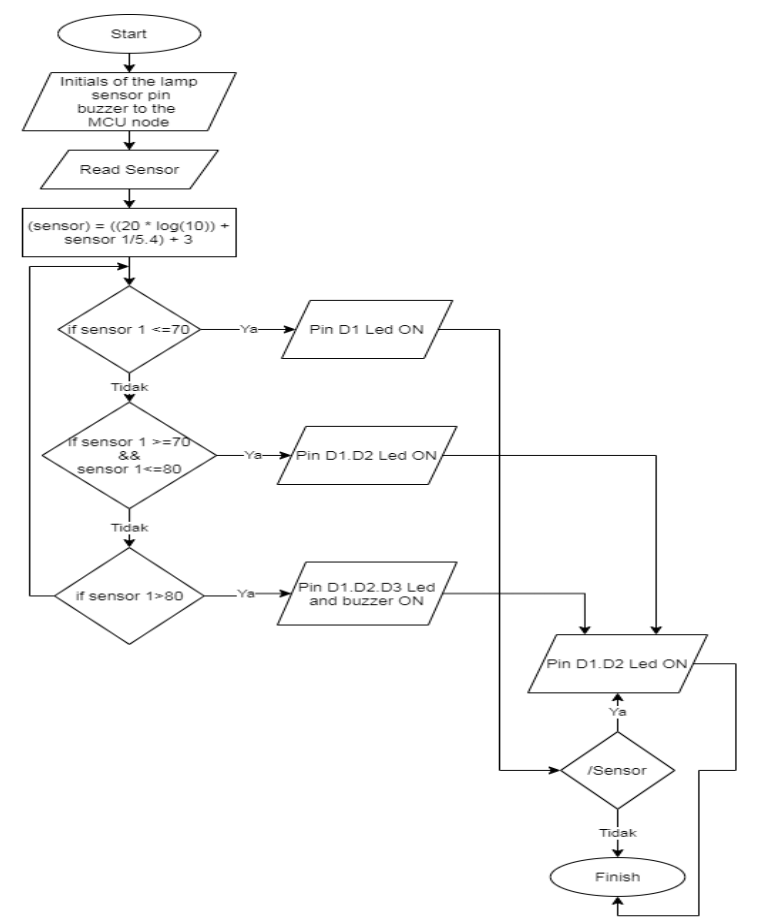

Picture 6. System Flowchart

\section{RESULT AND DISCUSSION}

In principle, to operate this noise detector by connecting a DC power supply to AC mains current. By using a power supply the mains voltage will be stable. After the power is connected to the NodeMCU, it will be distributed throughout the equipment. After the sensor turns on, the first process, namely the sound sensor, captures and reads the sound, after which the data obtained will be processed. The work tool process can be seen in Picture 7 .

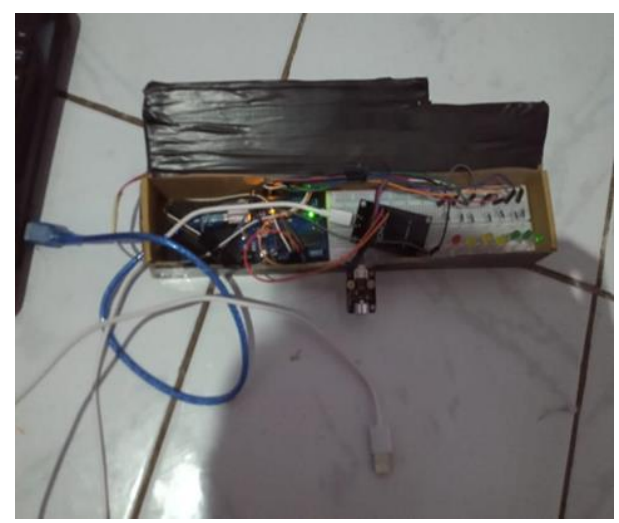

Picture 7. The work process of the tool

The first work process, namely the sound sensor detects sound with a mik on the sound sensor. then it will convert the vibration signal into an electrical signal (in the form of analog data) and then the electrical signal will be processed at NodeMCU using a formula. after the $\mathrm{db}$. value is obtained, a comparison will be made and will be adjusted to the predetermined qualifications. If the higher the sound voltage that is captured, the more lights will be turned on. Then the results that have been processed and the data obtained will be sent and displayed to the telegram. The sound sensor work process can be seen in Picture 8 .

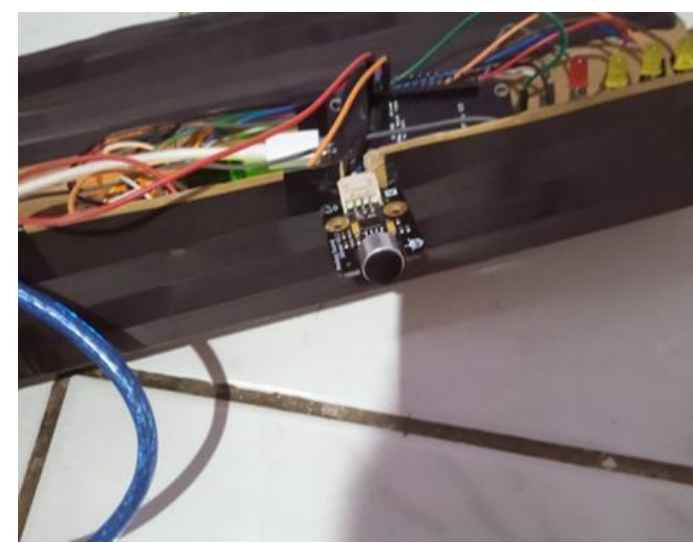

Picture 8. Sound sensor work process

\section{CONCLUSION}

To make a prototype tool for detecting noise in the research center and standardization of the NodeMCUbased Samarinda industry, which is needed, namely NodeMCU as the main hardware microcontroller and as a link to telegram, Analog sound sensor to capture sound voltage which is later forwarded to the LED, and buzzer as a marker and at the same warning indicator .

Based on the results of the Calibration test by comparing the sensor value with the values in the Sound Level Meter Application and the EXTECH 407764 Getting the sensor calibration values that are not the same but for the sensor value range is not too far due to the different device sensitivity. 
Based on the test results, the prototype of the Sound Detector can function properly, where each device functions properly and notifications are also sent according to the conditions made.

To get maximum results, we should use a microcontroller with much better quality, add more than one sensor to improve the work quality system on the tool and can add the output results in graphical form so that they can be analyzed and know clearly the level of statistical increase in the numbers on the tool. the. The ESP8266 NodeMCU can use a higher version such as the ESP32 because it has higher specifications and can speed up work on delivery. We recommend using a stable connection for sensor readings and using additional electrical power temporarily during a power cut. Those are the conclusions and suggestions that the writer can convey. Hopefully it will be useful for further research and be useful for everyone.

\section{REFERENCES}

Andrianto, H. \& Aan Delfiani .2016, Arduino Fast Learning and Programming. Bandung: Informatics.

Dinata, A. 2018. Fun Coding with Micropython. Jakarta: PT. Elex Media Komputindo.

Ellison, T. 2018. NodeMCU ESP 12E Datasheet. https://nodemcu.readthedocs.io/en/master/, Accessed 26 April 2018.

Habibullah, T, DA 2012. Implementation of the Nagios Network Monitoring System with the Event Handler and Telegram Messenger Notifications, Journal of MULTINETICS Vol: 2 (1) .15.

Hardyanto, RH 2017. Concept of Internet of Things in Web-Based Learning, Journal of Informatics Dynamics Vol: 6 (1) .89.

Hardyanto, RH 2017. Concept of Internet of Things in Web-Based Learning, Journal of Informatics Dynamics Vol: 6 (1) .87-97

Hidayat, AD Bambang S., Chess BW. 2019. Noise Level Detector based on Internet of Things as a Control Media for Library Room Comfort, AVITEC Journal. Vol: 1 (1) .99

Kadir, A. 2013. A Practical Guide to Studying Microcontroller Applications and Programming Using Arduino. Yogyakarta: CV Andi Offset.

Kalengkongan, T. S, Dringhuzen J. Mamahit, Sherwin RUA Sompie, 2018. Design of Arduino UnoBased Noise Detection Tool, Journal of Electrical and Computer Engineering Vol: 7 (2) 183-186.

Malau, Nya D., Replace RSM, Anastasia K. 2017. Analysis of Traffic Noise Levels on the Highway, Journal of EduMatSains Vol: 2 (1) 90.

Mulyana, A., Syam SN, 2012. Design of Motorcycle Exhaust Noise Test Equipment Based on PIC16F877A Microcontroller, Journal of Unikom Computer Systems. Vol: 1 (2). 11.

NodeMCU. 2014. NodeMCU Connect Thing EASY. http://www.nodemcu.com/in accessed on 5 October 2017.
Persada, Y., Achmad R. \& Muhammad R. 2012. Design and Realization of Vehicle Sound Noise Detector in Decibels. Description. : Telecommunication Engineering, Faculty of Applied Sciences, TelkomNodeMCU University. 2014. NodeMCU Connect Thing EASY. (Http://www.nodemcu.com/index_en.html), accessed 5 October 2017.

Pioto, RL 2014, Secure Instant Messaging, Master Thesis, Department of Computer Science and Engineer, Master Thesis, Frankfurt University.

Pressman, R. 2012. Software Engineering Practitioner Approach 7th Edition (Book 1). Yogyakarta: Publisher Andi.

Saftari, F. 2015. Cool Robotics Project with Arduino. PT.Elex Media Komputindo.

Siregar, AWP 2018. Noise Level Indicator in the Arduino-Based Workshop. Journal Vol: 1 (1) 21

Suhartono, J. 2016, Alpha Testing, https://sis.binus.ac.id / 2016/12/16 / alpha-testing /, accessed February 8, 2020

Syahwil. 2013. Simple Arduino Programming Technique. Surabaya: Gramedia

Syam, R. 2013. Basic Textbook Series of Sensor Engineering, Hasanuddi University, Faculty of Engineering

Yatini, I. 2010. Flowcharts, Algorithms and programming using the $\mathrm{C}++$ language. Yogyakarta: Graha Science.

Yudhanto, Y. 2018. Introductory Guide to Learning Hardware and Software: Troubleshooting Laptops.

Yurindra. 2017. Software Engineering. Yogyakarta: Deepublish. 